Supporting Information

\title{
Ethanol Electrooxidation Catalyzed by Tungsten Core@Palladium Shell
}

\section{Nanoparticles}

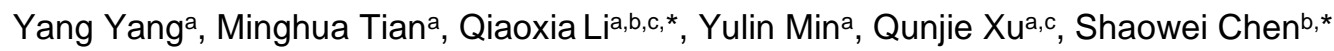

a Shanghai Key Laboratory of Materials Protection and Advanced Materials in Electric Power, College

of Environmental and Chemical Engineering, Shanghai University of Electric Power, 2588 Changyang

Road, Yangpu District, Shanghai 200090, China

${ }^{b}$ Department of Chemistry and Biochemistry, University of California, 1156 High Street, Santa Cruz,

CA 95064, USA

c Shanghai Institute of Pollution Control and Ecological Security, Shanghai 200090, China

*E-mail: liqiaoxia@shiep.edu.cn (Q.X.L.), shaowei@ucsc.edu (S.W.C.) 

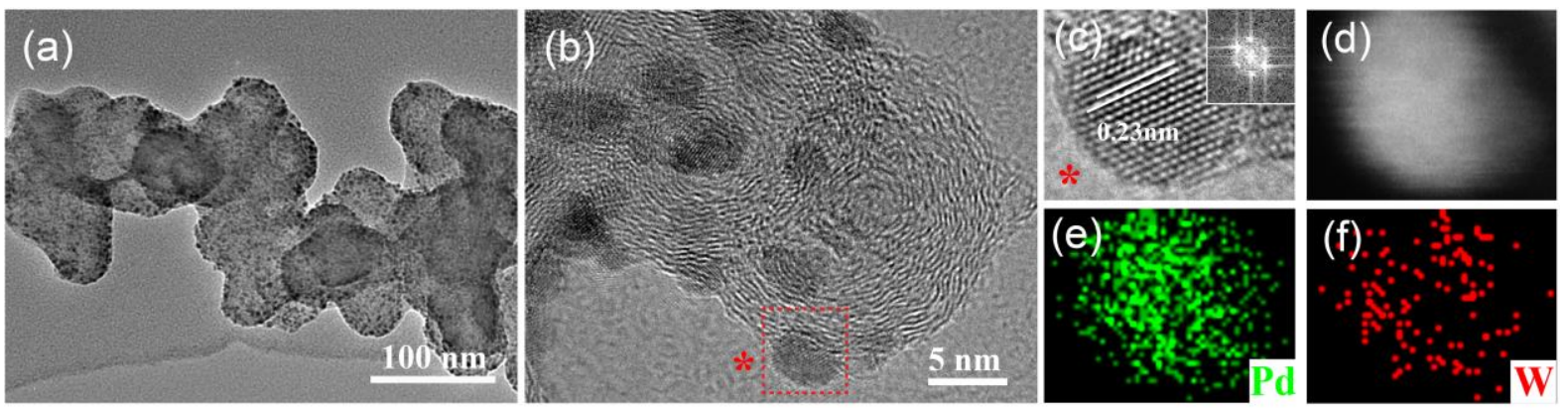

Figure S1. (a) TEM and (b) HRTEM images of W@Pd/C-O. (c) Magnified HRTEM image of a single W@Pd NP. Inset is the selected area electron diffraction patterns. (d) Dark-field TEM image of a single W@Pd NP and the corresponding EDS elemental maps for (e) Pd and (f) W.
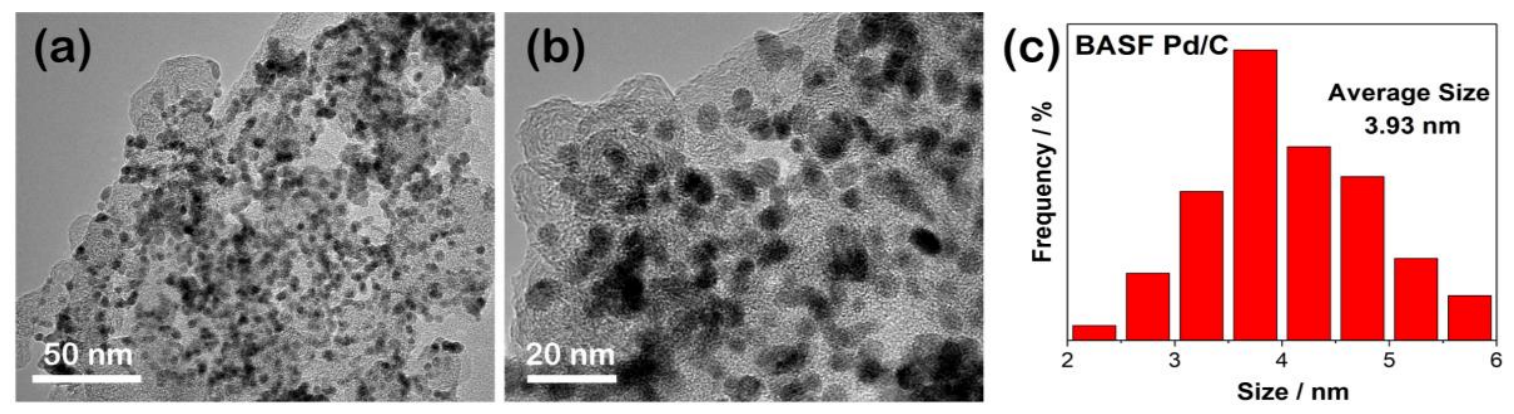

Figure S2. $(a-b)$ TEM images of BASF Pd/C, and (C) the corresponding core size histogram. 


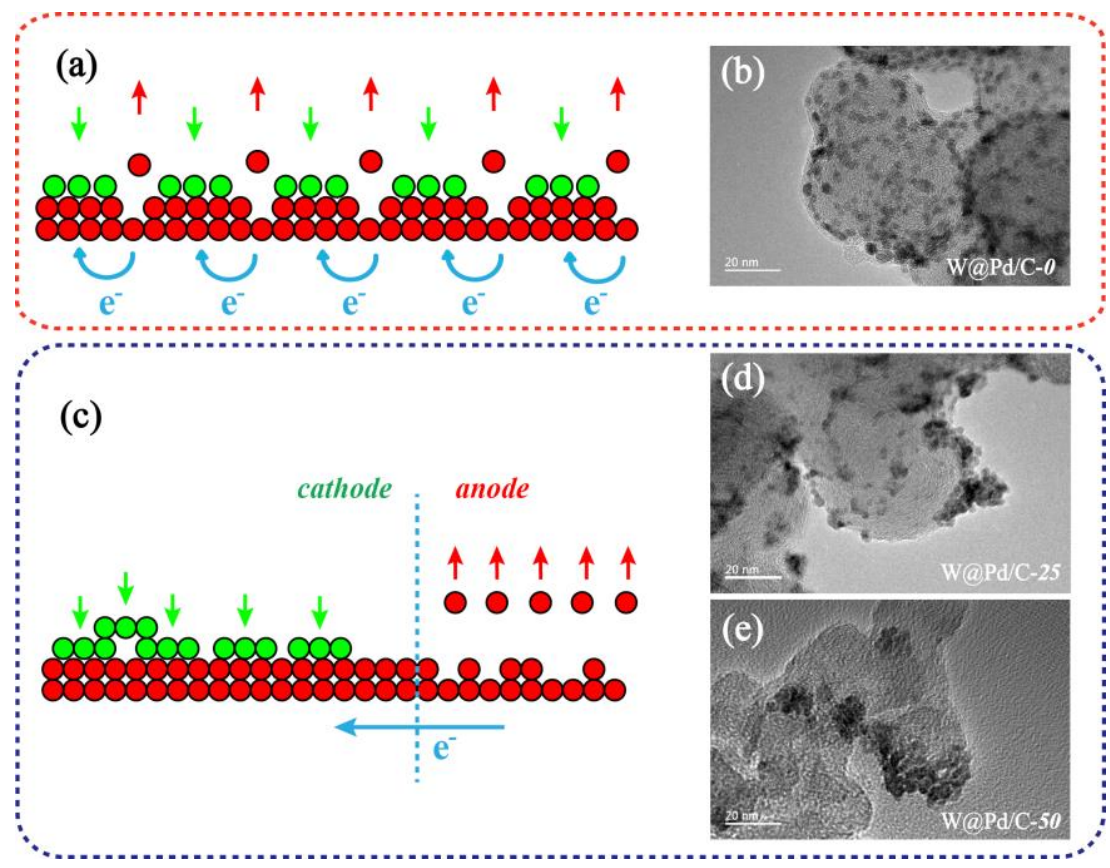

Figure S3. (a) Formation schematic and (b) TEM image of the W@Pd/C-O catalyst. (c) Formation schematic and TEM images of the (d) W@Pd/C-25 and (e) W@Pd/C-50 catalysts. Red spheres represent $\mathrm{W}$ and green spheres represent $\mathrm{Pd}$.

Galvanic replacement reaction (GRR) is a self-sacrificial template method, which is equivalent to a working nano-galvanic cell. The dissolved metal (W) is anode, and the deposited metal (Pd) is the cathode. Without lattice restrictions, corrosion of the anode metal and deposition of the cathode metal is random, which is helpful in producing nucleation centers and reducing size of the nanoparticles. In the present study, by controlling the reaction temperature, three samples of W@Pd/C-0,W@Pd/C-25, and W@Pd/C-50 were prepared (Figure S1). From the TEM images (panels b,d,e), one can see that the agglomeration of nanoparticles became apparent with increasing reaction temperature. For instance, in the W@Pd/C-0 sample (Figure S1b), the nanoparticles were dispersed on the carbon support surface without agglomeration. By contrast, nanoparticles in W@Pd/C-25 (Figure S1d) became irregular in shape and uneven in size distribution, whereas in W@Pd/C-50 (Figure S1e), extensive agglomeration of nanoparticles can be seen. The effect of temperature on the GRR kinetics is illustrated in Figure S1. At low temperature (panel a), several cathodes and anodes are uniformly distributed on a W nanoparticle, leading to breaking up of the substrate into ultra-small Pd-W bimetallic nanoparticles; whereas at higher temperature (panel c), GRR is facilitated at the end of the W nanoparticles, and anodic reaction at the other, leading to agglomeration of the resulting nanoparticles. 


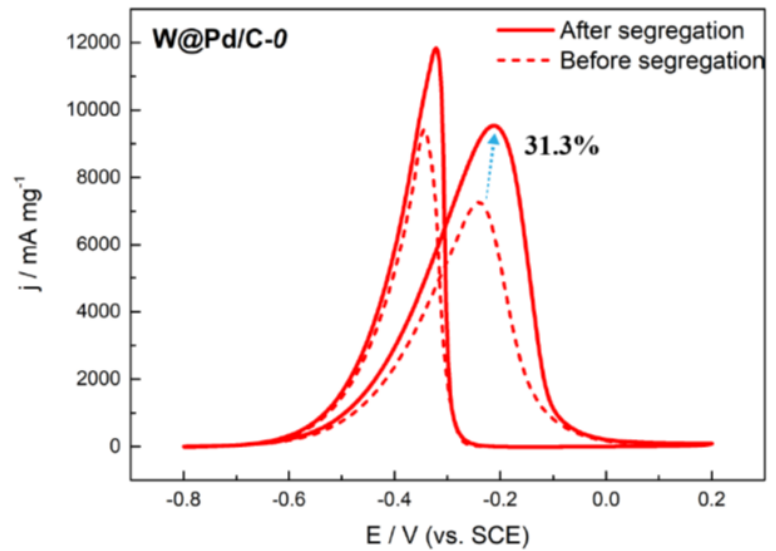

Figure S4. CVs of W@Pd/C-0 before and after segregation in a $1.0 \mathrm{M} \mathrm{NaOH}+1.0 \mathrm{M} \mathrm{C}_{2} \mathrm{H}_{5} \mathrm{OH}$ solution at the scan rate of $50 \mathrm{mV} \mathrm{s}^{-1}$. 
Table S1. Comparison of the EOR mass activity for various Pd-based electrocatalysts

\begin{tabular}{|c|c|c|c|}
\hline Catalyst & $I_{p}\left(m A / m g_{P d}\right)$ & $\mathrm{I}_{3600 \mathrm{~s}}\left(\mathrm{~mA} / \mathrm{mg}_{\mathrm{Pd}}\right)$ & Ref. \\
\hline W@Pd/C & 9535.5 & 763 & This work \\
\hline $\mathrm{Pd} @ \mathrm{~g}-\mathrm{C}_{3} \mathrm{~N}_{4} / \mathrm{GC}$ & 2156 & --- & Ref. 4 \\
\hline $\mathrm{Pd}_{40} \mathrm{Ni}_{43} \mathrm{P}_{17}$ & $\begin{array}{c}4950 \\
(100 \mathrm{mV} / \mathrm{s})\end{array}$ & $\begin{array}{c}215.4 \\
(2000 \mathrm{~s})\end{array}$ & Ref. 9 \\
\hline Pd/ATN-BP & 5023.8 & 867 & Ref. 13 \\
\hline $\mathrm{Pd} / \mathrm{MnO} 2 / \mathrm{GNRs}$ & 2510 & 380 & Ref. 14 \\
\hline $\mathrm{Pd} / \mathrm{PANI} / \mathrm{Pd}$ & 360 & $\begin{array}{c}40 \\
(2500 \mathrm{~s})\end{array}$ & Ref. 35 \\
\hline three-layer core/shell PtCu NPs/C & 1650 & --- & Ref. 41 \\
\hline PdCuP nanowires & 6670 & ca. 1400 & S1 \\
\hline Au80@Pd20/C & $\begin{array}{c}826.2 \\
(20 \mathrm{mV} / \mathrm{s})\end{array}$ & ca. 100 & S2 \\
\hline PdAg single-crystalline nanowires & 2840 & $\begin{array}{c}570 \\
(2000 \mathrm{~s})\end{array}$ & S3 \\
\hline $\mathrm{PdBi}-\mathrm{Bi}(\mathrm{OH})_{3}$ nanochains & 5300 & $\begin{array}{c}>1000 \\
(20000 \mathrm{~s})\end{array}$ & S4 \\
\hline $\ln _{3} \mathrm{Pd}_{2} / \mathrm{C}$ & 2820 & $\begin{array}{c}675.8 \\
(2100 \mathrm{~s})\end{array}$ & S5 \\
\hline
\end{tabular}

(S1) Lv, H.; Sun, L.; Xu, D.; Ma, Y.; Liu, B. When ternary PdCuP alloys meet ultrathin nanowires: Synergic boosting of catalytic performance in ethanol electrooxidation. Appl Catal B: Environ 2019, 253, 271-277.

(S2) Silva, L. S. R.; Almeida, C. V. S.; Meneses, C. T.; Batista, E. A.; Santos, S. F.; Eguiluz, K. I. B.; Salazar-Banda, G. R. AuPd/C core-shell and alloy nanoparticles with enhanced catalytic activity toward the electro-oxidation of ethanol in alkaline media. Appl Catal B: Environ 2019, 251, 313325.

(S3) Lv, H.; Wang, Y.; Lopes, A.; Xu, D.; Liu, B. Ultrathin PdAg single-crystalline nanowires enhance ethanol oxidation electrocatalysis. Appl Catal B: Environ 2019, 249, 116-125.

(S4) Yuan, X.; Zhang, Y.; Cao, M.; Zhou, T.; Jiang, X.; Chen, J.; Lyu, F.; Xu, Y.; Luo, J.; Zhang, Q.; Yin, $\mathrm{Y} . \mathrm{Bi}(\mathrm{OH}) 3 / \mathrm{PdBi}$ Composite Nanochains as Highly Active and Durable Electrocatalysts for Ethanol Oxidation. Nano Lett 2019, 19, 4752-4759.

(S5) Chen, Y.-J.; Chen, Y.-R.; Chiang, C.-H.; Tung, K.-L.; Yeh, T.-K.; Tuan, H.-Y. Monodisperse ordered indium-palladium nanoparticles: synthesis and role of indium for boosting superior electrocatalytic activity for ethanol oxidation reaction. Nanoscale 2019, 11, 3336-3343. 